\section{It's the 21st century: isn't it past time to ban menthol cigarette sales?}

\author{
Ruth E Malone
}

Mentholated cigarettes, introduced in the 1920 s, ${ }^{1}$ were once marketed in ways that falsely implied they were healthier than other cigarettes, and these beliefs persist among some consumers even today. ${ }^{2}$ Advertising even suggested that menthol cigarettes had medicinal qualities, marking them the cigarette of choice when a smoker was ill. The cooling effects and minty flavour of menthol also masked the harshness of smoke and made cigarettes easier to inhale. As such, they were also seen by tobacco companies as useful 'starter products' for beginning smokers, including youth.

Menthol cigarette use today varies greatly by country and social demographics. In Australia, for example, menthol cigarette use has dropped greatly overall $^{3}$ and now accounts for only a small portion of the market. In the Philippines, by contrast, the proportion of menthol smokers among all smokers has been estimated at $60 \% .^{4}$ In the USA, while overall smoking prevalence decreased between 2008-2010 and 2012-2014, the proportion of menthol smokers appears to be increasing. Further, youth smokers are the most likely age group to use menthol cigarettes, ${ }^{5}$ perhaps not surprising given that menthol marketing preferentially targets youth, African-Americans and other marginalised groups. ${ }^{6}$ Today, such marketing includes price promotions to lure lower income and youth smokers. Print advertising also links menthol with images of sociality, sexuality and 'naturalness', the latter perpetuating the deceptive implication that menthol cigarettes are 'healthier' than other cigarettes.

Because menthol appears to make smoking initiation easier, offers no health benefit, and may be associated with greater addiction or difficulty in quitting smoking, scientific groups have urged that policymakers ban menthol in tobacco products. ${ }^{7}$ Some have tried, but to date too few have succeeded. Brazil announced a ban on menthol and other flavours in 2012, but it was challenged by the tobacco industry and has not been implemented. The Canadian province of Nova Scotia, however,

Correspondence to Professor Ruth E Malone, Department of Social and Behavioral Sciences, School of Nursing, University of California, San Francisco, CA 94118, USA; ruth.malone@ucsf.edu successfully banned menthol cigarettes starting in 2015, quickly followed by Alberta, ${ }^{8}$ and the ban has now been extended nationwide in Canada. In the UK and European Union, a phaseout of small packs is coming ahead of a planned complete menthol ban in $2020 .^{9}$ One challenge to regulation has been the tobacco industry's emphasis on the mixed results of science on individual disease effects from menthol cigarette use, arguing they are no more likely than other cigarettes to cause diseases. This narrow focus has been critiqued as conveniently omitting the public health perspective, in which the social justice and broader population impacts of menthol become clearer. ${ }^{10}$

In the USA in 2011, the Tobacco Products Scientific Advisory Committee of the federal Food and Drug Administration (FDA), after a review of the evidence, stated that removal of place would benefit public health. ${ }^{11}$ The FDA subsequently performed further independent evaluation, concluding that sufficient evidence suggests that menthol is associated with increased smoking initiation and greater addiction. ${ }^{12}$ However, despite intense pressure, particularly from African-American tobacco control leaders whose communities were blanketed with aggressive, innovative menthol cigarette marketing during earlier decades, ${ }^{13} 14$ the FDA has still not acted to ban menthol.

Other US jurisdictions are not waiting for FDA to act. Several cities have worked to enact bans on sales of menthol tobacco products within certain distances from schools, and San Francisco, California recently proposed an ordinance banning the sale of menthol cigarettes and other tobacco products with flavours across the entire city. With the support of the mayor and supervisors, this landmark measure is expected to pass. A similar ordinance has been introduced in Oakland, California. ${ }^{15}$ Predictably, the tobacco industry has reacted aggressively. For example, RJ Reynolds, seller of the top menthol brand in the USA, recently enlisted prominent nationally known black leaders in a campaign designed to link menthol restrictions with the issue of police harassment in black communities, suggesting that mentholated cigarettes from the market- menthol bans would 'criminalize black smokers'. ${ }^{16}$ In a series of tobacco company-supported 'dialogues' around the country, however, such assertions were publicly challenged by public health leaders from the African-American community. Tobacco companies' fight to keep menthol suggests that this policy measure definitely passes the "tobacco industry scream test" ${ }^{\text {"1 }}$ by which to appraise the likely effectiveness of public health policy measures. Almost a century of Big Tobacco's menthol deception scam is enough: it is past time to ban sales of menthol cigarettes.

Competing interests None declared.

Provenance and peer review Not commissioned; internally peer reviewed.

(C) Article author(s) (or their employer(s) unless otherwise stated in the text of the article) 2017. All rights reserved. No commercial use is permitted unless otherwise expressly granted.

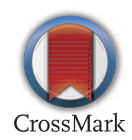

To cite Malone RE. Tob Control 2017;26:359-360.

Tob Control 2017;26:359-360.

doi:10.1136/tobaccocontrol-2017-053862

\section{REFERENCES}

1 Proctor RN. Golden holocaust: origins of the cigarette catastrophe and the case for abolition. Berkeley: University of California Press, 2011

2 Anderson SJ. Marketing of menthol cigarettes and consumer perceptions: a review of tobacco industry documents. Tob Contro/ 2011;20(Suppl 2):ii20-8.

3 King B, White V, Balmford J, et al. The decline of menthol cigarette smoking in Australia, 1980-2008. Nicotine Tob Res 2012;14:1213-20.

4 Giovino GA, Sidney S, Gfroerer JC, et al. Epidemiology of menthol cigarette use. Nicotine Tob Res 2004;6(Supp 1):67-81.

5 Villanti AC, Mowery PD, Delnevo CD, et al. Changes in the prevalence and correlates of menthol cigarette use in the USA, 2004-2014. Tob Control 2016;25(Suppl 2):ii14-20.

6 Richardson A, Ganz O, Pearson J, et al. How the industry is marketing menthol cigarettes: the audience, the message and the medium. Tob Control 2015;24:594-600.

7 World Health Organization Study Group on Tobacco Product Regulation. Banning menthol in tobacco products. 2016 http://apps.who.int/iris/bitstream/ 10665/205928/1/9789241510332_eng.pdf?ua=1;

8 Framework Convention Alliance. Canadian provinces first in world to ban menthol flavouring. 2015. http://www.fctc.org/fca-news/opinion-pieces/1328canadian-provinces-first-to-ban-menthol-flavouring\# sthash.QTLZ3xHy.dpuf

9 Brooks-Pollock T. Menthol cigarettes banned by EU under stringent new tobacco laws. Independent. 2016 http://wwwindependentcouk/news/uk/ home-news/the-eu-is-banning-menthol-cigarettesa7037346html

10 Gardiner P, Clark PI. Menthol cigarettes: moving toward a broader definition of harm. Nicotine Tob Res 2010;12(Suppl 2):S85-93.

11 Food and Drug Administration Tobacco Products Scientific Advisory Committee. Menthol cigarettes and public health: Review of the scientific evidence and recommendations. 
2011 https://wayback.archive-it.org/7993/

20170405201731/https://www.fda.gov/downloads/ AdvisoryCommittees/CommitteesMeetingMaterials/ TobaccoProductsScientificAdvisoryCommittee/ UCM269697.pdf

12 U.S. Food and Drug Administration. Preliminary scientific evaluation of the possible public health effects of menthol versus nonmenthol cigarettes. https://www.fda.gov/downloads/ucm361598.pdf

13 Yerger VB, Przewoznik J, Malone RE. Racialized geography, corporate activity, and health disparities: tobacco industry targeting of inner cities.

$J$ Health Care Poor Underserved 2007;18:10-38.

14 Tobacco Control Legal Consortium et al. Citizens Petition asking the U.S. Food and Drug Administration to Prohibit Menthol as a Characterizing Flavor in cigarettes, 2013. http://www.aacr.org/ AdvocacyPolicy/GovernmentAffairs/Documents/tclcfdacitizenpetition-menthol-2013_ F3F578.pdf

15 Pershan CSF. Oakland could ban Flavored tobacco Products including Menthol Cigarettes: SFIST, 2017. http://sfist.com/2017/04/19/sf_could_ban_flavored_ tobacco_produ.php

16 Levin M. Blowing smoke: tobacco giant uses Al Sharpton, other black leaders to combat menthol restrictions: Salon, 2017. http://www.salon.com/ 2017/02/12/blowing-smoke-r-j-reynolds-uses-alsharpton-other-black-leaders-to-combat-mentholrestrictions_partner/

17 Chapman S. Public health advocacy and tobacco control: making smoking history. Oxford, UK: Blackwell Publishing, 2007.

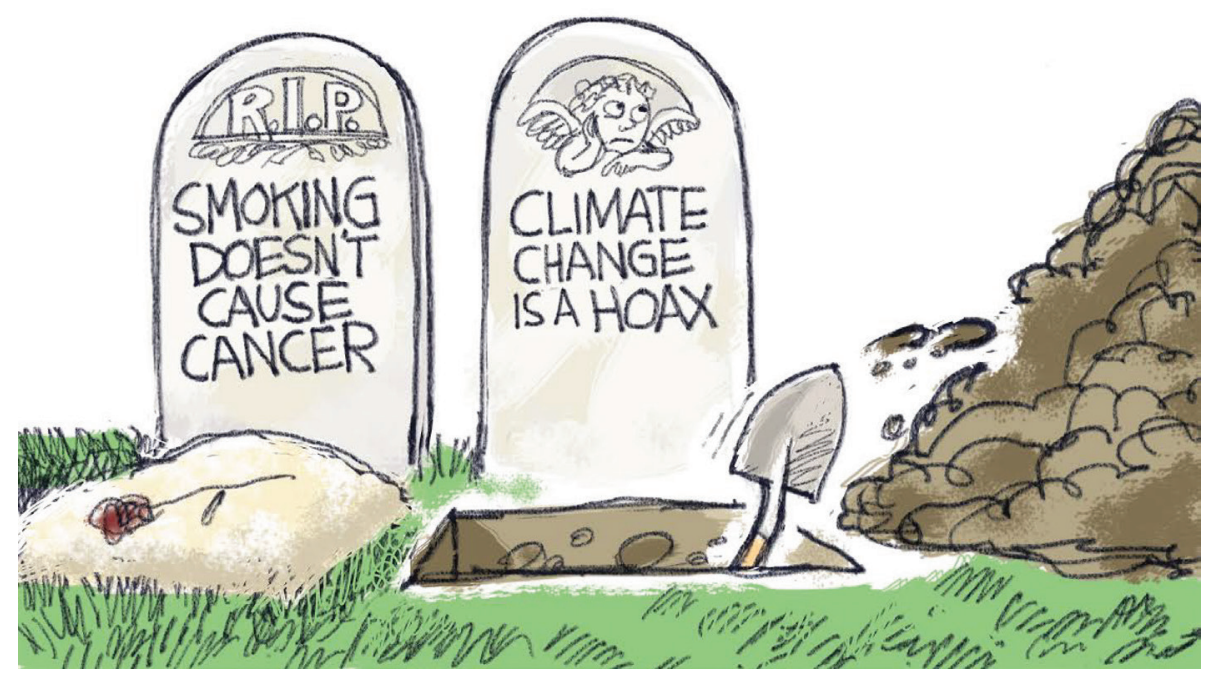

